Journal of Mathematics and Statistics 4 (2): 65-69, 2008

ISSN 1549-3644

(C) 2008 Science Publications

\title{
Power Series Solution for a Two-step Reactive-diffusive Equation with Variable Pre-exponential Factor
}

\author{
${ }^{1}$ Adebile, E.A., ${ }^{1}$ O.K. Koriko and ${ }^{2}$ U.S. Idiong \\ ${ }^{1}$ Department of Mathematical Sciences, Federal University of Technology, Akure \\ ${ }^{2}$ Department of Mathematics, Adeyemi College of Education, Ondo, Nigeria
}

\begin{abstract}
We discussed in this research a power series method for solution of a two-step reactivediffusive equation with variable pre-exponential factor. A transformation was used to fit in the geometry of the model to allow an asymptotic series expansion which is invoked in a two compartmental regions with respect to the spatial variable. Adequate matching conditions were used at the interface between the two regions. The results were displayed graphically and compared with the previous work in the literature.
\end{abstract}

Key words: Reactive-diffusive equation, two-step reaction, exothermic chemical reaction, variable pre-exponential factor

\section{INTRODUCTION}

Studies on combustion abound in the literature. A number of investigators have considered works in relation to chemical kinetics, thermodynamics, fluid mechanics and transport processes. In the industry rapid exothermic reaction processes which take place with the evolution of large amount of heat are very important. Energy released by a chemical explosion generally occurs from exothermic reactions.

Alao and Ayeni ${ }^{[3]}$ in their research established the condition for the existence and uniqueness of solution for a transformed mathematical model describing a viscous reacting flow. They used the Arrhenius term step reaction and considered that the activation energy is small.

Furthermore, Alao ${ }^{[2]}$ working after their former work; generalized the viscous reacting flow. Similarly, solutions were investigated and the numerical solutions for the resulting differential equation were obtained. Adegbie and Ayeni ${ }^{[1]}$ in their study discussed the existence and uniqueness of solution of a nonhomogenous branched chain reaction with slow radical recombination.

Okoya $^{[10]}$ brought to light a new analytical solution for the Frank-Kamenetskii parameter $\delta$ in the space in the special case of $\mathrm{n}=2, \mathrm{Q}_{2}=0$ corresponding to the sensitized reaction. The analytical solution is in terms of Bernoulli's numbers, and it is thus in accordance with the numerical integration for which $\beta(<<1)$ is very small and for $\beta \rightarrow 0$. It reduces to the solution for the Frank-Kamenetskii case

$$
\left.\exp \left(-\theta_{\mathrm{m}}\right) \cosh ^{-1}\left[\exp \frac{\theta_{\mathrm{m}}}{2}\right]\right\}^{2}
$$

$\theta_{\mathrm{m}}$ is the dimensionless temperature at the centre of the slab. He also determined the transitional values $\delta, \beta$ and $\theta_{\mathrm{m}}$ numerically Olanrewaju et al. ${ }^{[11]}$ investigated the effects of the geometry of vessel in the notation. They discovered that the maximum temperature in a non-uniform vessel occurs at the centre and that the maximum temperature for diverging or converging vessel is greater than the one of the diverging vessel

\section{MATHEMATICAL FORMATION}

The governing equation for the steady temperature, $\mathrm{T}$, of a one-dimensional Slab with boundaries lying in the coordinate plane $x= \pm a$ may be written in term of physical variables,

$$
\lambda \frac{d^{2} T}{d x^{2}}+\rho Q_{1} A\left(\frac{R T}{v \lambda \rho}\right) \exp +\rho Q_{2} E\left(\frac{R T}{v \lambda \rho}\right) \exp \left(\frac{-E_{2}}{R T}\right)=0
$$

with the corresponding boundary conditions

$$
\mathrm{T}=\mathrm{T}_{0} \text { on } \mathrm{x}= \pm \mathrm{a}
$$

$\mathrm{T}_{0}$, in the initial temperature. All other variable or parameters are deferent in the Nomenclature.

Conversing that the consumption of the consultable in neglected, if $\mathrm{d}_{2}=0$, it has been show experimentally

Corresponding Author: Adebile, E.A., Department of Mathematical Sciences, Federal University of Technology, Akure 
that the model can predict the critical ignition temperature for variety of combustible material (Bowes $^{[5]}$ ).

Using the following non-dimensional variables.

$$
\overline{\mathrm{x}}=\frac{\mathrm{x}}{\mathrm{a}}, \theta=\frac{\left(\mathrm{T}-\mathrm{T}_{0}\right) \mathrm{E}}{\mathrm{RT}_{0}^{2}}, \beta=\frac{\mathrm{RT}_{0}}{\mathrm{E}}, \mathrm{r}=\frac{\mathrm{E}_{2}}{\mathrm{E}_{1}}
$$

on equation (2) and (3) we have after dropping the bars

$$
\begin{aligned}
& \frac{\mathrm{d}^{2} \theta}{\mathrm{dx}^{2}}+\sigma_{1}(1+\beta \mathrm{Q})^{\mathrm{n}} \exp \left(\frac{\theta}{1+\beta \theta}\right) \\
& +\sigma_{2}(1+\beta \theta)^{\mathrm{m}} \exp \left(\frac{\mathrm{r} \theta}{1+\beta \theta}\right)=0 \\
& \theta=0 \text { on } \mathrm{x} \pm 1
\end{aligned}
$$

where

$$
\begin{aligned}
& \delta_{1}=\frac{\mathrm{a}^{2} \mathrm{Q}_{1} \mathrm{E}_{1} \mathrm{~A}\left(\frac{\mathrm{kT}}{\mathrm{vhp}}\right)^{\mathrm{n}} \exp \left(\frac{-\mathrm{E}_{1}}{\mathrm{RT}_{0}}\right)}{\lambda \mathrm{RT}_{0}^{2}}, \\
& \delta_{2}=\frac{\mathrm{a}^{2} \mathrm{Q}_{2} \mathrm{EE}_{1} \mathrm{~B}\left(\frac{\mathrm{KT}_{0}}{\mathrm{vhp}}\right)^{\mathrm{m}} \exp \left(\frac{-\mathrm{rE}_{1}}{\mathrm{RT}_{0}}\right)}{\lambda \mathrm{RT}_{0}^{2}}
\end{aligned}
$$

In (4) $\delta_{1}$ and $\delta_{2}$ are the Frank-Kamenetskii parameters which are the measures of the exothermicity of the reactions.

A number of attempts for the solution to determine the factors that control thermal ignition of combustion materials relating to the model in Eq. (4) and (5) have been done. Frank-Kamenetskii ${ }^{[8]}$ obtained a closed form solution. Considering that $\mathrm{Q}_{2}=0$, the limit of large activation energy $(\varepsilon \rightarrow 0)$ Bowes ${ }^{[5]}$, Ward and Van De Velde ${ }^{[12]}$ established the possibility of perturbation solution under physically reasonable assumption when $\mathrm{Q}_{2}=0$ and $\mathrm{n}=0$. Numerical and asymptotic solutions were obtained for some Biot numbers and for some realistic conditions Burnell et al..$^{[7]}$ and Bilingham ${ }^{[4]}$. In these work we are using the spatial induced converging series method to obtain solution to the model in (4) and (5)

Substituting (B), (C) and (D) in Eq. (2) and Taking the coefficients of $y^{0}, y^{1}, y^{2}$

\section{Order $\mathbf{y}^{\mathbf{0}}$ :}

$$
2 \mathrm{a}_{2}+\mathrm{v}^{\mathrm{n}}\left(1+\lambda \mathrm{a}_{0}+\frac{\lambda^{2} \mathrm{a}_{0}^{2}}{2}\right) \delta_{1}+\mathrm{v}^{\mathrm{m}}\left(1+\mathrm{r} \lambda \mathrm{a}_{0}+\frac{\lambda_{2} \mathrm{r}_{2} \mathrm{a}_{0}^{2}}{\mathrm{r}}\right) \delta_{2}=0
$$

where

$$
v=1+\beta \mathrm{a}_{0}
$$

Order $\mathbf{y}^{(1)}$ :

$$
\begin{aligned}
& 6 a_{3}+\delta_{1}\left[\begin{array}{l}
v^{n}\left(\lambda a_{1}-\lambda^{2} \beta a_{0} a_{1}\right)+ \\
\left(\lambda^{2} a_{0} a_{1}-\lambda^{3} \beta a_{0} a_{1}\right)
\end{array}\right. \\
& +n v^{n-1} a_{1}\left(1+\lambda a_{0}+\frac{\lambda^{2} a^{0}}{2}\right)^{2}
\end{aligned}
$$

Order $\mathbf{y}^{(2)}$ :

$$
\begin{aligned}
& 12 \mathrm{a}_{4}+\delta_{1}\left[\begin{array}{l}
v^{\mathrm{n}}\left\{\mathrm{a}_{2} \lambda-\lambda^{2} \beta \mathrm{a}_{0} \mathrm{a}_{2}-\lambda^{2} \beta \mathrm{a}_{1}^{2}+\lambda^{3} \beta \mathrm{a}_{0} \mathrm{a}_{1}^{2}\right. \\
+\lambda \mathrm{a}_{0}\left(\mathrm{a}_{2} \lambda-\lambda^{2} \beta \mathrm{a}_{0} \mathrm{a}_{2}\right.
\end{array}\right. \\
& \left.-\lambda^{2} \beta \mathrm{a}_{0} \mathrm{a}_{2}-\lambda^{2} \beta \mathrm{a}_{1}^{2}+\lambda^{3} \beta \mathrm{a}_{0} \mathrm{a}_{1}^{2}\right) \\
& +\mathrm{n} v^{\mathrm{n}-1} \mathrm{a}_{2}\left(1+\lambda \mathrm{a}_{0}+\frac{\lambda^{2} \mathrm{a}_{1}^{2}}{2}\right)+ \\
& \mathrm{n} \frac{(\mathrm{n}-)}{2} v^{\mathrm{n}-2} \mathrm{a}_{1}^{2}\left(1+\lambda \mathrm{a}_{0}+\frac{\lambda^{2} \mathrm{a}_{0}^{2}}{2}\right) \\
& +\delta_{21}\left[\begin{array}{l}
v^{\mathrm{m}}\left(\mathrm{a}_{3} \lambda-\lambda^{2} \beta \mathrm{a}_{0} \mathrm{a}_{2}-\lambda^{2} \beta \mathrm{a}_{1}^{2}+\right. \\
\mathrm{r}^{3} \beta \mathrm{a}_{0} \mathrm{a}_{1}^{2}+\lambda \mathrm{a}_{0}\left(\mathrm{a}_{2} \lambda-\lambda^{32} \beta \mathrm{a}_{0} \mathrm{a}_{2}-\right.
\end{array} \lambda^{2} \beta \mathrm{a}_{1}^{2}\right. \\
& \left.+\lambda^{3} \beta \mathrm{a}_{0}^{1} \mathrm{a}_{1}\right)+\mathrm{m} v^{\mathrm{m}-1} \mathrm{a}_{2}\left(1+\mathrm{r} \lambda \mathrm{a}_{0}+\frac{\mathrm{r}^{2} \lambda^{2} \mathrm{a}^{0}}{2}\right)^{2} \\
& +\frac{\mathrm{m}(\mathrm{m}-1)}{2} \mathrm{v}^{\mathrm{m}-2}\left(1+\mathrm{r} \lambda \mathrm{a}_{0}+\frac{\mathrm{r}^{2} \lambda^{2}}{2} \mathrm{a}_{0}^{2}\right) \mathrm{a}_{1}^{2}=0
\end{aligned}
$$

using the boundary condition

$$
\begin{aligned}
& \theta^{(i)}=\sum_{1=0}^{\infty} a_{i} y^{i}=a_{0}+a_{1} y+a_{2} y^{2}+a_{3} y^{3} \ldots \ldots \ldots . . . i=0 \\
& \theta^{(i)}(0)=a_{0}=0
\end{aligned}
$$

Hence, for, Eq. (5)

$$
\mathrm{a}_{3}=-\frac{1}{2}\left[\mathrm{v}^{\mathrm{n}} \delta_{1}+\mathrm{v}^{\mathrm{m}} \delta_{2}\right]=\text { cons } \tan \mathrm{t}=\mathrm{A}_{2}
$$

where

$$
\mathrm{V}^{\mathrm{n}} \equiv \mathrm{V}^{\mathrm{m}}=1
$$

from (6) we have

$$
\begin{aligned}
& 6 \mathrm{a}_{3}+\delta_{1}\left[n V^{\mathrm{n}-1} \mathrm{a}_{1}+\lambda \mathrm{V}^{\mathrm{n}} \mathrm{a}_{1}\right]+\delta_{2}\left[\mathrm{mV}^{\mathrm{m}-1} \mathrm{a}_{1}+\mathrm{V}^{\mathrm{m}} \lambda \mathrm{a}_{1}\right]=0 \\
& \mathrm{a}_{3}=-\frac{1}{6}\left[n \mathrm{nV}^{\mathrm{n}-1} \mathrm{a}_{1}+\lambda \mathrm{V}^{\mathrm{n}} \mathrm{a}_{1}\right]+\delta_{2}\left[\mathrm{mV}^{\mathrm{m}-1} \mathrm{a}_{1}+v^{\mathrm{m}} \mathrm{r} \lambda \mathrm{a}_{1}\right] \mathrm{a}_{1} \equiv \mathrm{A}_{3} \mathrm{a}_{1}
\end{aligned}
$$


from (8) we have

$$
\begin{aligned}
& 12 a_{4}+\delta_{1}\left[v^{n}\left(a_{2} \lambda-\lambda^{2} \beta a_{1}^{2}\right)+n v^{n-1} a_{2}+\frac{n(n-1)}{2} v^{n-2} a_{1}^{2}\right] \\
& +\delta_{2}\left[\mathrm{~V}^{\mathrm{m}}\left(\mathrm{a}_{2} \lambda-\lambda^{2} \beta \mathrm{a}_{1}^{2}\right)+m \mathrm{v}^{\mathrm{m}-1} \mathrm{a}_{2}+\frac{\mathrm{m}(\mathrm{m}-1)}{2} \mathrm{v}^{\mathrm{m}-2} \mathrm{a}_{1}^{2}\right]=0 \\
& a_{4}=-\frac{1}{12}\left(\begin{array}{l}
\left\{\left[\frac{n(n-1)}{2} v^{n-2}-v^{n} \lambda^{2} \beta\right] \delta_{1}+\right. \\
{\left[\frac{m(m-1)}{2} v^{m-2}=v^{m} \lambda^{2} \beta\right] \delta_{2}}
\end{array}\right) \\
& \left.\left.\mathrm{a}_{1}^{2}+\left\{\lambda \mathrm{v}^{\mathrm{n}}+\mathrm{n} \mathrm{v}^{\mathrm{n}-1}\right\} \delta_{1}+\left\{\lambda \mathrm{v}^{\mathrm{m}}-\mathrm{m} \mathrm{v}^{\mathrm{m}-1}\right] \delta_{2}\right\} \mathrm{a}_{2}\right) \\
& \cong \mathrm{A}_{4} \mathrm{a}_{1}^{2}+\mathrm{A}_{4}
\end{aligned}
$$

Recall that

$$
\theta^{(i)}(y)=a_{0}+a_{1} y+a_{2} y^{2}+\ldots . .=f\left(a_{1}\right)
$$

Where: $\mathrm{a}_{0}=0$

For outer region $\theta^{0}$

$$
\sum_{1=0}^{\infty} b_{j}(1-y)^{j}=\sum_{j=0}^{\infty} b j z^{j}
$$

Where:

$$
\begin{aligned}
& z=1-y \\
& d z=-d y \\
& d z^{2}=d^{2}
\end{aligned}
$$

Since the series $\sum_{\mathrm{j}=0}^{\infty} b j z^{j}$ is similar to the first series. Its form of coefficients will be similar

$$
\begin{aligned}
& b_{2}=B_{2} \\
& b_{3}=B_{3} b_{1} \\
& b_{4}=B_{4} b_{1}^{2}+B_{4}^{*}
\end{aligned}
$$

\section{METHOD OF SOLUTION}

The non-linear boundary valued problem in the Eq. (2) and (3) is solved using a converging power series.

The power series for the inner-region $(0, \alpha), \alpha \leq$ $1 / 2$, so given by

$$
\theta^{(i)}(\alpha)=\sum_{j=0}^{\infty} a_{j} \alpha^{j}
$$

and the power series for the outer-region a

$$
\theta^{\circ}(\alpha)=\sum_{1=0}^{\infty} b_{j}(1-\alpha)^{j}
$$

Substituting Eq. (10) into Eq. (2) and collecting the coefficients of $x^{0}, x^{1}, x^{2}$; we have:

$$
\begin{aligned}
& a_{2}=-\left[v^{n}+v^{m}\right] / 2 \\
& a_{3}=-a_{1}\left[n v^{n-1} \delta_{1}+v^{m} \lambda \delta_{2}+m v^{m-1}\right] / 6 \\
& a_{4}=\frac{-1}{12}\left[\begin{array}{l}
\left(n v^{n-1}+v^{m} r\right) \delta_{1} a_{2}+ \\
\left\{\begin{array}{l}
1 / 2 n(n-1) v^{n-1} \delta_{1} \\
+m v^{m-1} \delta_{2}+m(m-1) \\
v^{m-1} \delta_{2}+m r \lambda \delta_{2}+1 / 2 r^{2} \delta_{2}
\end{array}\right\} a_{1}+n \lambda v^{n-1} \delta_{1} a_{1}^{2}
\end{array}\right]
\end{aligned}
$$

Similarly, substituting the series in the Eq. (11) into the Eq. (2) and collecting the coefficients of $z^{0}, z^{1}$, $\mathrm{z}^{2}$ (where $\left.\mathrm{z}=1-\mathrm{y}\right)$. We have

$$
\mathrm{b}_{2}=-\left[\mathrm{v}^{\mathrm{n}}+\mathrm{v}^{\mathrm{m}}\right] / 2
$$

$$
\begin{gathered}
\mathrm{b}_{3}=-\mathrm{a}_{1}\left[\mathrm{n} v^{\mathrm{n}-1} \delta_{1}+v^{\mathrm{m}} \lambda \delta_{2}+m v^{\mathrm{m}-1}\right] / 6 \\
\mathrm{~b}_{4}=\frac{-1}{12}\left[\begin{array}{l}
\left(\mathrm{n} v^{\mathrm{n}-1}+v^{\mathrm{m}} \mathrm{r}\right) \delta_{1} \mathrm{a}_{2}+ \\
\left\{\begin{array}{l}
1 / 2 \mathrm{n}(\mathrm{n}-1) v^{\mathrm{n}-1} \delta_{1} \\
+\mathrm{m} v^{\mathrm{m}-1} \delta_{2}+\mathrm{m}(\mathrm{m}-1) v^{\mathrm{m}-1} \delta_{2} \\
+\mathrm{mr} \lambda \delta_{2}+1 / 2 \mathrm{r}^{2} \delta_{2}
\end{array}\right.
\end{array}\right\} \mathrm{a}_{1}+\mathrm{n} \lambda v^{\mathrm{n}-1} \delta_{1} \mathrm{a}_{1}^{2}
\end{gathered}
$$

Using the boundary condition,

$$
\theta^{\mathrm{i}}(0)=\theta^{\circ}(0)=0
$$

We have

$$
\mathrm{a}_{0}=0, \mathrm{~b}_{0}=0
$$

Since there is continuity of heat transfer within the slab, then

$$
\theta^{i}=\theta^{\circ} \frac{d \theta}{d x}=\frac{d \theta^{\circ}}{d x} \text { at } x=\alpha
$$


Using the conditions in equation (19), we have:

$$
\begin{aligned}
& \mathrm{N}_{1} \mathrm{a}_{1}^{2}+\mathrm{N}_{2} \mathrm{~b}_{1}^{2}+\mathrm{N}_{3} \mathrm{a}_{1}+\mathrm{N}_{4} \mathrm{~b}_{1}=\mathrm{N}_{5} \\
& \mathrm{M}_{1} \mathrm{a}_{1}^{2}+\mathrm{M}_{2} \mathrm{~b}_{1}^{2}+\mathrm{M}_{3} \mathrm{a}_{1}+\mathrm{M}_{4} \mathrm{~b}_{1}=\mathrm{M}_{5}
\end{aligned}
$$

After much algebra, we have 4th degree the polynomial

$$
\mu_{1} a_{1}^{4}+\mu_{2} a_{1}^{3}+\mu_{3} a_{1}^{2}+\mu_{4} a_{1}+\mu_{5}=0
$$

And similarly for $b_{1}$. After obtaining $a_{1}$ and $b_{1}$, the $\mathrm{a}_{2}, \mathrm{a}_{3}, \mathrm{a}_{4}$ and $\mathrm{b}_{2}, \mathrm{~b}_{3}, \mathrm{~b}_{4}$ are obtained as follows:

$$
\begin{aligned}
& \mathrm{a}_{1}=1.442053 \\
& \mathrm{a}_{2}=-0.43925 \\
& \mathrm{a}_{3}=-0.154486 \\
& \mathrm{a}_{4}=-0.5841154 \\
& \mathrm{~b}_{1}=1.442053 \\
& \mu_{1}=1.346913 \times 10^{-4} \\
& \mu_{2}=2.321132 \times 10^{-2} \\
& \mu_{3}=11315.67 \\
& \mu_{4}=-632427.7 \\
& \mu_{5}=-2.05849 \times 10^{10}
\end{aligned}
$$

Hence, the solutions for the inner and outer regions are obtained.

\section{DISCUSSION OF RESULTS AND CONCLUSION}

The steady state solutions of temperature as shown in Fig 1-3 reveal the solution obtained by previous works in the literature and that the curve is continuous at the merging point. This is also an improvement over the previous work by other authors is that it caters for two-step activation energy rather than one which is simple to be comprehended.

\section{NOMENCLATURE}

$\lambda=$ Thermal conductivity of the material

$\mathrm{Q}_{1}=$ The heat of reaction in step one

$\mathrm{Q}_{2}=$ The heat of reaction in step two

$\mathrm{A}=$ The rate constant in step one

$\mathrm{B}=$ He rate constant in step two

$\mathrm{m}, \mathrm{n}=$ The exponent

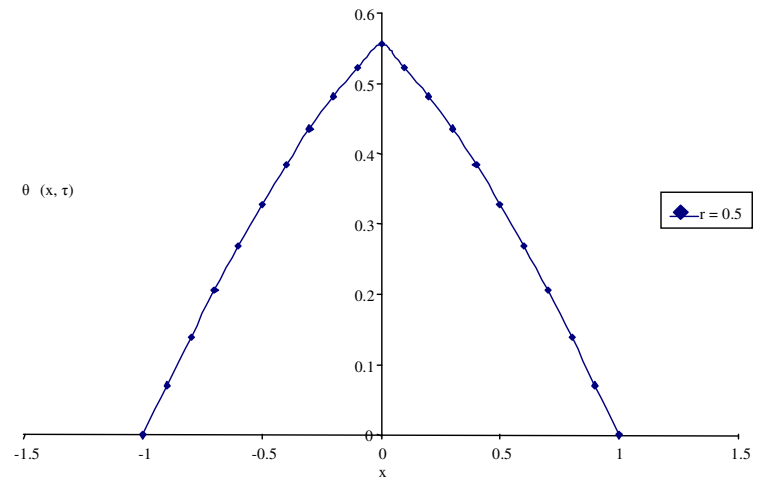

Fig. 1: The graph of temperature $\theta(\mathrm{x}, \tau)$ against position for $\delta 1=0.3064, \delta 2=0.5721, v=1 \lambda=$ $1, \beta=0.001, r=-0.5$

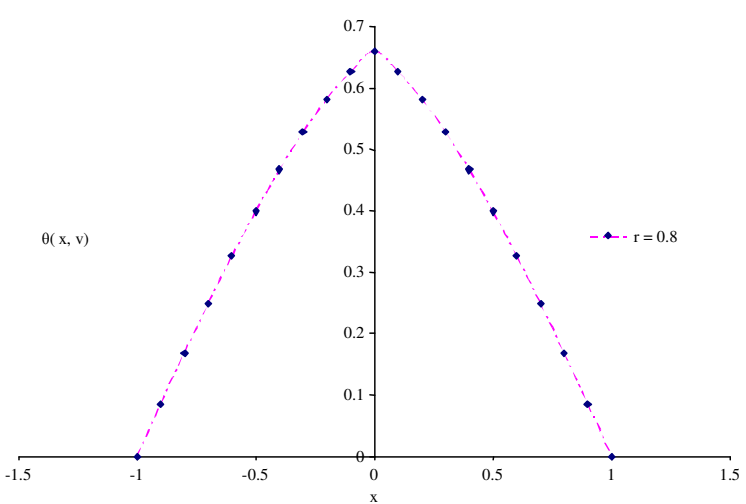

Fig. 2: Graph of temperature against position $\theta(\mathrm{x}, \tau)$ for $\delta_{1}=0.3064, \delta_{2} 0.5721, \beta=0.001, \rho-0.8$

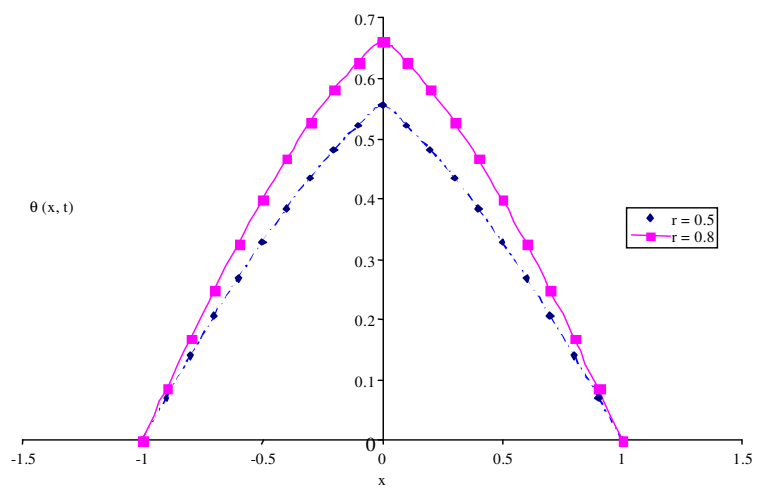

Fig. 3: Shows the graph of temperature $\theta(\mathrm{x}, \tau)$ against position different values of $\mathrm{r}$ at $\delta_{1}=0.3064, \delta_{2}$ $0.5721, \mathrm{v}=1 \mathrm{a}=1, \mathrm{a} 1=0.5$ and $\beta=0.001$

$\mathrm{E}_{\mathrm{i}}, \mathrm{i}=1.2=$ The activation energies

$\mathrm{r}=$ The ratio of the activation energies 


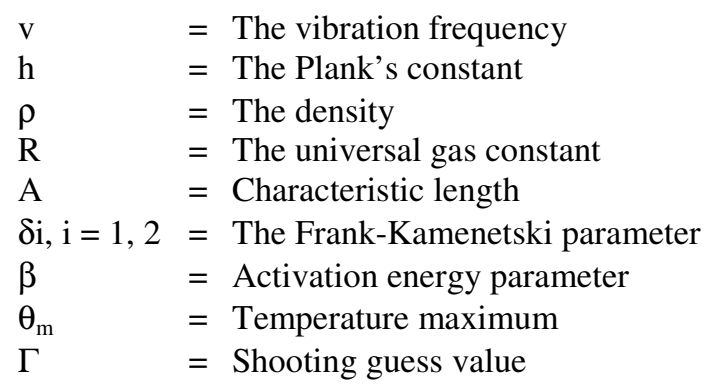

\section{REFERENCE}

1. Adegbie, K.S. and R.O. Ayeni, 2003. On the existence and uniqueness of solution of steady branched-chain explosion with slow radial recombination. Nig. J. Math. Appl., 16: 1-7.

2. Alao, F.I., 2004. Numerical analysis of self-similar solution for generalized reacting visions flows. Sci. Focus, 8: 73-75.

3. Alao, F.I. and R.O. Ayeni, 2000. Existence and uniqueness of self-similar solution for a viscous reacting flow. J. Nig. Assoc. Math. Phys., 5: 177-182.

4. Billigham, J., 2000. Steady state solutions for strongly exothermic ignition in symmetric geometries. IMA J. Applied Math., 65: 283-313.
5. Bowes, P.C., 1984. Self-Heating evaluation and controlling the hazards. 42: 147-154.

6. Buckmaster, J.P. and G.S.S. Ludford, 1982. Theory of Lammar Flames. Cambridge, London NY New Rochelle.

7. Burnell, J.G., J.G. Graham-Eagle, B.F. Gray and A.C. Wake, 1989 Determination of critical ambient temperature for thermal ignition. IMA J. Applied Math., 42: 147-154.

8. Frank-K Kamenetskii, D.A., 1969. Diffusion and Heat Transfer in Chemical Kinetics. Plenum Press, New York.

9. Kenneth, K.K., 2005. Principles of Combustion. John Wiley's sons, Inc, Hoboken, New Jersey.

10. Okoya, S.S., 2004. Reactive-diffusive equation with variable pre-exponential factors. Mechanic Res. Commun., 31: 263-267.

11. Olarenrewaju, P.O., R.O. Ayeni, A.O. Ajala, O. Adebimpe and A.O. Ajayi, 2006. On the existence and uniqueness result for a two-step reactive diffusive equation with variable preexponential factor. J. Nig. Math. Phys., 10: 403-408.

12. Ward, M.J. and E.F. Van de Velde, 1992. The onset of thermal runaway in partially insulated or cooled reactors. IMA J. Applied Math., 48: 53-83. 